\title{
Cytogenetic variability among Bradyporinae species (Orthoptera: Tettigoniidae)
}

\author{
ElżBIETA WARCHAŁOWSKA-ŚLIWA ${ }^{1}$, BEATA GRZYWACZ1 ${ }^{1}$, ANNA MARYAŃSKA-NADACHOWSKA ${ }^{1}$, \\ Tatyana V. KARAMYSHEVA², Dragan P. CHOBANOV ${ }^{3}$ and KLaus-Gerhard HELLER ${ }^{4}$ \\ ${ }^{1}$ Institute of Systematics and Evolution of Animals, Polish Academy of Sciences, Kraków, Poland; \\ e-mails: warchalowska@isez.pan.krakow.pl; grzywacz@isez.pan.krakow.pl; maryanska@isez.pan.krakow.pl \\ ${ }^{2}$ Institute of Cytology and Genetics of the Siberian Branch of the Russian Academy of Sciences, Novosibirsk, Russia; \\ e-mail: kary@bionet.nsc.ru \\ ${ }^{3}$ Institute of Biodiversity and Ecosystem Research, Bulgarian Academy of Sciences, Tsar Osvoboditel 1, 1000 Sofia, Bulgaria; \\ e-mail:dchobanov@gmail.com \\ ${ }^{4}$ Grillenstieg 18, 39120 Magdeburg, Germany; e-mail: Heller.volleth@T-Online.de
}

\begin{abstract}
Key words. Orthoptera, Ephippigerini, Bradyporini, karyotype evolution, chromosome fusion, B chromosomes, FISH, rDNA
\end{abstract}
\begin{abstract}
Chromosomes of six European species (one with two subspecies) of Orthoptera belonging to the tribes Ephippigerini and Bradyporini were analyzed using C-banding, Ag-NOR, DAPI (AT-rich)/CMA 3 (GC-rich) staining and fluorescence in situ hybridization (FISH) using the $18 \mathrm{~S}$ rDNA and (TTAGG) ${ }_{n}$ telomeric probes with the aim to better understand chromosomal organization and evolutionary relationships between genera and subgenera within and across both tribes. The evolution of karyotypes was studied in terms of changes in chromosome number $(2 \mathrm{n})$ and morphology (FN, the fundamental number - i.e. the number of chromosome arms including the $\mathrm{X}$ chromosome). The ancestral $2 \mathrm{n}=31$ was reduced to $2 \mathrm{n}=29(\mathrm{FN}=31)$ and $27(\mathrm{FN}=31)$ by one or two Robertsonian fusions in the Ephippigerini. Whereas in the Bradyporini $2 \mathrm{n}=27(\mathrm{FN}=32)$ as a result of two Robertsonian translocations and a pericentric inversion in the X chromosome. The quantity of heterochromatin in GC-rich regions distinguished the karyotypes of Ephippigerini (only a single CG-rich band on one autosome pair) from those of Bradyporini (CG-rich bands on all chromosomes). FISH using the 18S rDNA probe localized 1-3 rDNA clusters to autosomes and/or to the $\mathrm{X}$ chromosome in all species examined. The rDNA loci coincided with active NORs as determined by Ag-NOR staining. A comparison of the location of the single $\mathrm{NOR} / \mathrm{rDNA}$ in two species of the genus Steropleurus (Ephippigerini) suggests that the reduced chromosome number in $S$. pseudolus results from a Robertsonian fusion between two pairs of autosomes, one of them carrying the NOR/rDNA as in $S$. stalii (and also in E. ephippiger). Whereas the karyotypes of three species of the genus Bradyporus, though showing the same chromosome number and morphology, differed in the number and distribution of NORs/rDNA sites [one autosomal in $B$. (B.) dasypus versus three in $B$. macrogaster and $B$. (C.) oniscus, two of them X-linked]. Trends in karyotype diversification of the taxa based on the present data and previous research are discussed. In some individuals belonging to the species Bradyporus (B.) dasypus and B. (C.) $m$. macrogaster B chromosomes (Bs) were detected: acrocentric (the smallest elements in the complement) and submetacentric (similar to medium-sized autosomes), respectively.
\end{abstract}

\section{INTRODUCTION}

The subfamily Bradyporinae Burmeister, 1838 (Orthoptera; Tettigoniidae) includes more than 160 species, distributed exclusively in the Palearctic region. At present it is subdivided into three tribes: Bradyporini, Ephippigerini and Zichyini (Eades et al., 2012). The status and classification of the group and its subgroups differ slightly between authors (e.g. Bradyporinae/-idae, Ephippigerini/ -idae/-inae). All members of the group are micropterous and flightless. Many Ephippigerini are medium-sized insects with a body length of a few centimeters, but some Bradyporini and Zichyini are quite large and heavy insects with a body weight reaching even over $20 \mathrm{~g}$ (D.P. Chobanov, unpubl. data). The Bradyporini and Zichyini live mostly near the ground, while the Ephippigerini typically inhabit bushes and trees. As regards evolutionary systematics, the tribe Ephippigerini, which is quite large, has never been comparatively analyzed except for descriptive research (Peinado, 1990) or papers concerning single genera (e.g. Nadig, 1994; Pfau, 1996; Barat, 2007).
The same seems to be true of the Zichyini, a much smaller group (5 genera), studied taxonomically by Cejchan (1967). Recent molecular studies of this group cover only one (Zhou et al., 2009) or two (Bugrov et al., 2009) species. The tribe Bradyporini, divided into two genera, was investigated recently, at least partially. The phylogeny of the genus Pycnogaster, formerly considered a separate subfamily, was studied by Pfau (1988) and Pfau \& Pfau (1995), and the taxonomy of the Bradyporus species of Turkey was revised by Ünal (2011). However, the relationships between the genera and tribes are completely unexplored.

From a karyological point of view, the Bradyporinae is an interesting group with a wide range of diploid numbers of chromosomes $(2 \mathrm{n})$ varying in males from 31 , with an $\mathrm{X} 0$, to 22 , with a neo-XY sex determination mechanism. So far only 25 species of 12 genera, some of which include chromosome races, have been cytogenetically studied (reviewed by Warchałowska-Śliwa, 1998). The chromosomes of this subfamily have been occasionally examined using only the C-banding technique and NOR 
Ag-staining (Fernández-Piqueras et al., 1982, 1983a, b, c, 1984; Navas-Castillo et al., 1986; Warchałowska-Śliwa \& Bugrov, 1996, 1997).

The present study reports the cytogenetic characterization of six European species (one with two subspecies) representing two tribes: Ephippigerini, Ephippiger ephippiger, Steropleurus stalii and Steropleurus pseudolus, and Bradyporini, Bradyporus (Bradyporus) dasypus, Bradyporus (Callimenus) macrogaster macrogaster, Bradyporus (Callimenus) macrogaster longicollis and Bradyporus (Callimenus) oniscus. The physical characteristics of their karyotypes were analyzed using the classical methods of C-banding, silver impregnation (Ag-NORs), 4-6-diamidino-2-phenylindole (DAPI) staining and chromomycin $\mathrm{A}_{3}\left(\mathrm{CMA}_{3}\right)$ staining. Additionally, fluorescent in situ hybridization (FISH) using $18 \mathrm{~S}$ rDNA and (TTAGG) ${ }_{n}$ telomeric DNA probes were applied to the species. A comparison of rDNA-FISH results with those after silver impregnation enabled us to precisely locate the active NORs. The telomeric probe was used to mark chromosome ends and indicate possible evolutionary rearrangements of the chromosomes, such as fusions (López-Fernández et al., 2004). We have characterized the karyotypes of these taxa with the aim of identi- fying possible cytogenetic markers. It is the first step towards a better understanding of chromosomal organization and the evolution of relationships between genera and subgenera within and between both tribes.

\section{MATERIAL AND METHODS}

A total of 27 specimens of six Bradyporinae species (one with two subspecies) were collected in the field in Bulgaria, Poland, Greece, Spain, and Portugal, and one population was obtained from a laboratory culture. Information on where and when the specimens used in this study were collected is given in Table 1.

The gonads of nymphs and/or young adults were used to obtain the chromosomal preparations. The testes and ovarioles were excised, incubated in a hypotonic solution $(0.9 \%$ sodium citrate) and then fixed in ethanol : acetic acid $(3: 1)$. The fixed material was squashed in $45 \%$ acetic acid. Cover slips were removed using the dry ice procedure and the preparations air dried. C-banding was carried out according to Sumner (1972). Chromosomes were classified on the basis of the criteria proposed by Levan et al. (1964). The silver staining method (Ag$\mathrm{NO}_{3}$ ) for nucleolar organizer regions (NORs) was performed as previously reported (Warchałowska-Śliwa \& MaryańskaNadachowska, 1992). In order to reveal the molecular composition of C-heterochromatin, some slides were stained with $\mathrm{CMA}_{3}$ to reveal GC- and with DAPI to reveal AT-rich regions (Schweizer, 1976). Fluorescence in situ hybridization (FISH)

TABLE 1. Species of Bradyporinae: where and when collected.

\begin{tabular}{|c|c|c|}
\hline Species & $\begin{array}{l}\text { Localities collected, date (species number) and } \\
\text { where the voucher specimens are deposited }\end{array}$ & Geographical coordinates \\
\hline \multicolumn{3}{|l|}{ EPHIPPIGERINI } \\
\hline \multirow[b]{2}{*}{ Ephippiger ephippiger (Fiebig, 1784) } & Bulgaria; Iskar, 24.vi.2006 (1 ठ̊), ISEZ0168 & $43^{\circ} 27^{\prime} 18^{\prime \prime} \mathrm{N}, 24^{\circ} 14^{\prime} 24^{\prime \prime} \mathrm{E}$ \\
\hline & $\begin{array}{l}\text { Poland; Zamość, Wieprzecka Mt. } \\
\text { 25.vi.1997 }(1 \text { đ, 1 })\end{array}$ & $50^{\circ} 38^{\prime} 0^{\prime \prime} \mathrm{N}, 23^{\circ} 6^{\prime} 0^{\prime \prime} \mathrm{E}$ \\
\hline $\begin{array}{l}\text { Steropleurus stalii (Bolívar, 1878) } \\
=\text { Uromenus (Steropleurus) stalii (Bolivar, 1876) }\end{array}$ & $\begin{array}{l}\text { Spain; Caceres, Puerto de Tornavaces, } \\
\left.\text { 29.vi.2005 (3 } \text { o }^{*}\right), \text { WAR32-9,32-13,32-14 }\end{array}$ & $40^{\circ} 15^{\prime} 1^{\prime \prime} \mathrm{N}, 54^{\circ} 1^{\prime} 31^{\prime \prime} \mathrm{E}$ \\
\hline $\begin{array}{l}\text { Steropleurus pseudolus (Bolívar, 1878) } \\
=\text { Uromenus (Steropleurus) pseudolus (Bolivar, 1876) }\end{array}$ & $\begin{array}{l}\text { Portugal; Faro, Monchique Mt. } \\
\text { 18-19.vi.2005 (20) WAR21,25-4 }\end{array}$ & $37^{\circ} 15^{\prime} 5^{\prime \prime} \mathrm{N}, 8^{\circ} 33^{\prime} 22^{\prime \prime} \mathrm{W}$ \\
\hline \multicolumn{3}{|l|}{ BRADYPORINI } \\
\hline \multirow{5}{*}{ Bradyporus (Bradyporus) dasypus (Illiger, 1800) } & $\begin{array}{l}\text { Bulgaria; population A, Rupite Place, } \\
\text { 17.vi.2008 (1§) ISEZ0310 }\end{array}$ & $41^{\circ} 27^{\prime} 08^{\prime \prime} \mathrm{N}, 23^{\circ} 15^{\prime} 57^{\prime \prime} \mathrm{E}$ \\
\hline & $\begin{array}{l}\text { Bulgaria; population B, Nof Hursovo Vill., } \\
\text { 18.vi.2008 (2 } 0 \text {, ISEZ0313-14) } \\
\end{array}$ & $41^{\circ} 28^{\prime} 22^{\prime \prime} \mathrm{N}, 23^{\circ} 23^{\prime} 24^{\prime \prime} \mathrm{E}$ \\
\hline & $\begin{array}{l}\text { Bulgaria, population C, Plevun Vill., } \\
\text { 16.vi.2006 }(2 \hat{0}, 1 \text { 우 ISEZ0047-9 } \\
\end{array}$ & $41^{\circ} 28^{\prime} 24^{\prime \prime} \mathrm{N}, 26^{\circ} 00^{\prime} 20^{\prime \prime} \mathrm{E}$ \\
\hline & $\begin{array}{l}\text { Bulgaria; population D, K. Dimitrovo, } \\
\text { 16.vi.2010, }(1 \hat{\jmath}, 1 \uparrow)\end{array}$ & $43^{\circ} 57^{\prime} 02^{\prime \prime} \mathrm{N}, 27^{\circ} 42^{\prime} 04^{\prime \prime} \mathrm{E}$ \\
\hline & $\begin{array}{l}\text { Greece; population E, Karditsa, } \\
\text { near Ano Ktimeni, 15.vi.1998, (4ठ) }\end{array}$ & $39^{\circ} 05^{\prime} \mathrm{N}, 22^{\circ} 06^{\prime} \mathrm{E}$ \\
\hline \multirow{2}{*}{$\begin{array}{l}\text { Bradyporus (Callimenus) macrogaster macrogaster } \\
\text { (Lefebvre, 1831) }\end{array}$} & $\begin{array}{l}\text { Bulgaria; population A, E Rodopi Mts, } \\
\left.\text { Ivaylovgrad, 22.vi.2008 (2 } \widehat{\sigma}^{\star}\right) \\
\end{array}$ & $41^{\circ} 32^{\prime} 09^{\prime \prime} \mathrm{N}, 26^{\circ} 07^{\prime} 32^{\prime \prime} \mathrm{E}$ \\
\hline & $\begin{array}{l}\text { Bulgaria, population B, laboratory culture, } \\
\left.\text { 2010, Dragan, fix.20.vi.2010 (1 } \sigma^{\star}\right)\end{array}$ & $41^{\circ} 32^{\prime} 09^{\prime \prime} \mathrm{N}, 26^{\circ} 07^{\prime} 32^{\prime \prime} \mathrm{E}$ \\
\hline $\begin{array}{l}\text { Bradyporus (Callimenus) macrogaster longicollis } \\
\text { Fieber, 1853) }\end{array}$ & Bulgaria; Bosten vill., 20.vi.2010 (20) & $42^{\circ} 53^{\prime} \mathrm{N}, 23^{\circ} 06^{\prime} \mathrm{E}$ \\
\hline \multirow{2}{*}{ Bradyporus (Callimenus) oniscus (Burmeister, 1838) } & $\begin{array}{l}\text { Greece; Peloponnes, near Andritsena, } \\
\text { 14.vi.1997 (1 } 9),\end{array}$ & $37^{\circ} 27^{\prime} \mathrm{N}, 21^{\circ} 58^{\prime} \mathrm{E}$ \\
\hline & $\begin{array}{l}\text { Greece; Peloponnes, Ancient Likeo, } \\
\text { 14.vi.1997 (1 đ })\end{array}$ & $37^{\circ} 27^{\prime} \mathrm{N}, 21^{\circ} 55^{\prime} \mathrm{E}$ \\
\hline
\end{tabular}


TABLE 2. Comparison of number and morphology of chromosomes, the distribution of heterochromatin bands, NORs and rDNA on the chromosomes of the species of Bradyporidae examined.

\begin{tabular}{|c|c|c|c|c|c|c|}
\hline \multirow[t]{2}{*}{ Species } & \multirow{2}{*}{$\begin{array}{l}\text { 2n (in the male), FN and } \\
\text { chromosome morphology }\end{array}$} & \multirow[t]{2}{*}{ C-bands } & \multicolumn{2}{|c|}{$\begin{array}{c}\text { Position of fluorochrome } \\
\text { bands }\end{array}$} & \multirow[t]{2}{*}{ NOR } & \multirow[t]{2}{*}{ rDNA FISH } \\
\hline & & & DAPI+ & CMA3+ & & \\
\hline \multicolumn{7}{|l|}{ EPHIPPIGERINI } \\
\hline E. ephippiger & $\begin{array}{c}29, \mathrm{FN}=31 \\
\mathrm{~L} 1 \mathrm{~m}, \mathrm{M} 2-7 \mathrm{a}, \mathrm{S} 8-14 \mathrm{a}, \mathrm{Xa}\end{array}$ & $\begin{array}{l}\text { pe thin - all chromosomes; } \\
\text { M4 thin } \mathrm{t} ; \mathrm{M} 2 * \text { thin } \mathrm{i}\end{array}$ & - & $\mathrm{M} 2 * \mathrm{i}$ & M2 i & M2* \\
\hline S. stalii & $\begin{array}{c}29, \mathrm{FN}=31 \\
\mathrm{~L} 1 \mathrm{~m}, \mathrm{M} 2-7 \mathrm{a}, \mathrm{S} 8-14 \mathrm{a}, \mathrm{Xa}\end{array}$ & $\begin{array}{l}\text { pc thin - all chromosomes; } \\
\text { M4, M6 thick t; M2 i* }\end{array}$ & M4, M5 t & $\mathrm{M} 2 * \mathrm{i}$ & $\mathrm{M} 2 * \mathrm{i}$ & M2* \\
\hline S. pseudolus & $\begin{array}{c}27, \mathrm{FN}=31 \\
\mathrm{~L} 1, \mathrm{~L} 2 \mathrm{~m}, \mathrm{M} 3-6 \mathrm{a}, \mathrm{S} 7-13 \mathrm{a}, \mathrm{Xa}\end{array}$ & $\begin{array}{c}\text { pc thin - all chromosomes, L2*; } \\
\text { M3, M4* thick t; }\end{array}$ & $\begin{array}{l}\text { M3, M4* } \\
\text { M5 t }\end{array}$ & $\mathrm{L} 2 * \mathrm{pc}, \mathrm{M} 4 * \mathrm{t}$ & $\mathrm{L} 2 * \mathrm{pc}$ & $\mathrm{L} 2 *$ \\
\hline \multicolumn{7}{|l|}{ Bradyporini } \\
\hline $\begin{array}{l}\text { B. }(B .) \\
\text { dasypus }\end{array}$ & $\begin{array}{c}\text { 27, FN }=32 \\
\text { L1, L2m, M3-6a, S7-13a, Xm }\end{array}$ & $\begin{array}{c}\text { pc thin - M2-S13, X, L1* thick - } \\
\text { population C; } \\
\text { Ba heterochromatic - population B }\end{array}$ & L1* weak & $\begin{array}{l}\text { = C-bands } \\
\text { bright L1* pc, } \\
\text { Bs }\end{array}$ & $\mathrm{L} 1 * \mathrm{pc}$ & $\mathrm{L} 1 *$ \\
\hline $\begin{array}{l}\text { B. }(C .) \\
\text { macrogaster } \\
\text { macrogaster }\end{array}$ & $\begin{array}{c}\text { 27, FN = } 32 \\
\mathrm{~L} 1 \mathrm{~m}, \mathrm{M} 2 \mathrm{sm} / \mathrm{sa}, \mathrm{M} 3-8 \mathrm{a}, \mathrm{S} 9- \\
\text { 13a, Xm }\end{array}$ & $\begin{array}{c}\text { pc thin M2-S13, L1* - populations } \\
\text { A, B and X thick; } \\
\text { X on one arm thick i; M3 thin it; } \\
\text { Bm pe thin - population A }\end{array}$ & $=\mathrm{C}$-bands & $\begin{array}{c}=\mathrm{C} \text {-bands } \\
\text { bright } \mathrm{L} 1^{*} \\
\text { M3 it, X pc + i }\end{array}$ & $\begin{array}{l}\mathrm{L} 1, \\
\mathrm{X} \text { i, pc }\end{array}$ & $\begin{array}{l}\mathrm{L} 1^{*} \mathrm{pc} \\
\text { bright } \mathrm{X} \text { i; } \\
\text { weak X pc, }\end{array}$ \\
\hline $\begin{array}{l}\text { B. }(C .) \\
\text { macrogaster } \\
\text { longicollis }\end{array}$ & $\begin{array}{c}27, \mathrm{FN}=32 \\
\mathrm{~L} 1 \mathrm{~m}, \mathrm{M} 2 \mathrm{sm} / \mathrm{sa}, \mathrm{M} 3-8 \mathrm{a}, \mathrm{S} 9- \\
13 \mathrm{a}, \mathrm{Xm}\end{array}$ & $\begin{array}{c}\text { pc thin M2-S13, L1, X thick; } \\
\text { X on one arm thick i; M3 thin it }\end{array}$ & $=\mathrm{C}$-bands & $\begin{array}{l}\text { = C-bands } \\
\text { bright L1, M3 } \\
\text { it, } X \text { pc }+\mathrm{i}\end{array}$ & $\begin{array}{l}\text { L1, } \\
\mathrm{Xi}, \mathrm{pc}\end{array}$ & $\begin{array}{l}\text { L1 pc, } \\
\text { bright X i; } \\
\text { weak X pc, }\end{array}$ \\
\hline $\begin{array}{l}\text { B. }(C .) \\
\text { oniscus }\end{array}$ & $\begin{array}{c}27, \mathrm{FN}=32 \\
\mathrm{~L} 1 \mathrm{~m}, \mathrm{M} 2 \mathrm{sm} / \mathrm{sa}, \mathrm{M} 3-8 \mathrm{a}, \mathrm{S} 9- \\
13 \mathrm{a}, \mathrm{Xm}\end{array}$ & $\begin{array}{l}\text { pc thin L1-S13, X; M7-S9 thick t; } \\
\text { X on one arm thick } \mathrm{i}\end{array}$ & $=\mathrm{C}$-bands & $\begin{array}{l}=\mathrm{C} \text {-bands } \\
\text { bright } \mathrm{X} \mathrm{i}\end{array}$ & $\begin{array}{l}\text { L1, } \\
\mathrm{X} \mathrm{i,pc}\end{array}$ & $\begin{array}{l}\mathrm{L} 1 \mathrm{pc}, \\
\text { bright X i; } \\
\text { weak X pc, }\end{array}$ \\
\hline
\end{tabular}

FN - fundamental number of chromosome arms; (L) large-, (M) medium-, (S) small-sized autosomes; a - acrocentric, $\mathrm{m}$ - metacentric, sm - submetacentric, sa - subacrocentric; $\mathrm{pc}$ - paracentromeric, $\mathrm{i}$ - interstitial, it - interstitial near telomeric region; $\mathrm{t}$ - telomeric; *intraspecific variation of heterochromatin - thick/thin or present/absent; B - B chromosome.

with ribosomal 18S DNA (rDNA) and telomeric (TTAGG) DNA probes was performed according to Warchałowska-Śliwa et al. (2009). The probes were prepared and labelled as described in Warchałowska-Śliwa et al. (2009); the 18S rDNA probe used in this study was that amplified from genomic DNA of Isophya rammei (Orthoptera). Microscopy was performed using a Nikon Eclipse 400 fitted with a CCD DS-U1 camera and a set of standard filters. Lucia Image 5.0 software was used and images were processed and arranged with Adobe Photoshop. For each specimen, 15-20 meiotic divisions and at least two spermatogonial and/or oogonial metaphases were examined.

\section{RESULTS}

\section{Karyotypes}

The chromosome number $(2 \mathrm{n})$ and chromosome morphology (FN - the number of chromosome arms including the $\mathrm{X}$ chromosome) for each species/subspecies are shown in Table 2. A study of mitotic metaphase and meiotic plates of the Ephippigerini E. ephippiger and $S$. stalii showed $2 \mathrm{n}=29, \mathrm{FN}=31$ in males (Fig. 1a-d) and $2 \mathrm{n}=30, \mathrm{FN}=32$ and 34 in females, respectively (not shown), whereas $S$. pseudolus is characterized by $2 \mathrm{n}=$ $27, \mathrm{FN}=31$ in males (Fig. 1e, f). As regards Bradyporini species, B. (B.) dasypus (both subspecies), B. (C.) macrogaster macrogaster, $B$. (C.) macrogaster longicollis and $B$. (C.) oniscus have $2 \mathrm{n}=27, \mathrm{FN}=32$ in males (Fig. 1 $\mathrm{g}-1$ ) and $28, \mathrm{FN}=33$ in females (not shown). The chromosomes can be classified into three groups according their size: large (L), medium (M) and small (S) (Table 2).
The X chromosome is the second largest element in the set. All the species analyzed have the same sex determination system, X0 (male) and XX (female).

The various banding techniques revealed differences between species belonging to the two tribes and also among karyotypes with similar chromosome numbers (Table 2).

\section{Heterochromatin}

After both C-staining and DAPI/CMA 3 double-staining, some chromosome regions show either a positive $(+)$ or negative $(-)$ reaction with the stains or fluorochromes used, mainly depending on the base composition of the DNA molecule. Heterochromatin blocks can be characterized as DAPI-/CMA 3 + (GC-rich), DAPI+/CMA - (ATrich) or DAPI $+/ \mathrm{CMA}_{3}+$ (containing $\mathrm{AT}$ and $\mathrm{CG}$ bases). In E. ephippiger, the thin C-bands on most of the chromosomes were DAPI- (it was impossible to locate DAPIpositive bands), whereas only one region of the interstitial location on $\mathrm{M}_{2}$ was $\mathrm{CMA}_{3}+$ (Fig. 2a, b). Bright DAPI+ bands on $\mathrm{M}_{4}$ and $\mathrm{M}_{6}$ in $S$. stalii (Fig. 2c) and $\mathrm{M}_{3}, \mathrm{M}_{4}$ and $\mathrm{M}_{6}$ in S. pseudolus (Fig. 2e) were located terminally, being clearly associated with thick C-bands (Fig. $1 \mathrm{c}-\mathrm{f}$ ). In these species, the thin $\mathrm{C} / \mathrm{CMA}_{3}+$ bands present in the interstitial region on $\mathrm{M}_{2}$ in $S$. stalii (Fig. 2d) and in the paracentromeric region on $\mathrm{L}_{2}$ in $S$. pseudolus (Fig. 2f) were DAPI- (Fig. 2c, e). Thus, the composition of heterochromatin in these species shows a single GC-rich region. In contrast, $\mathrm{CMA}_{3}+$ regions differing in fluorochrome 

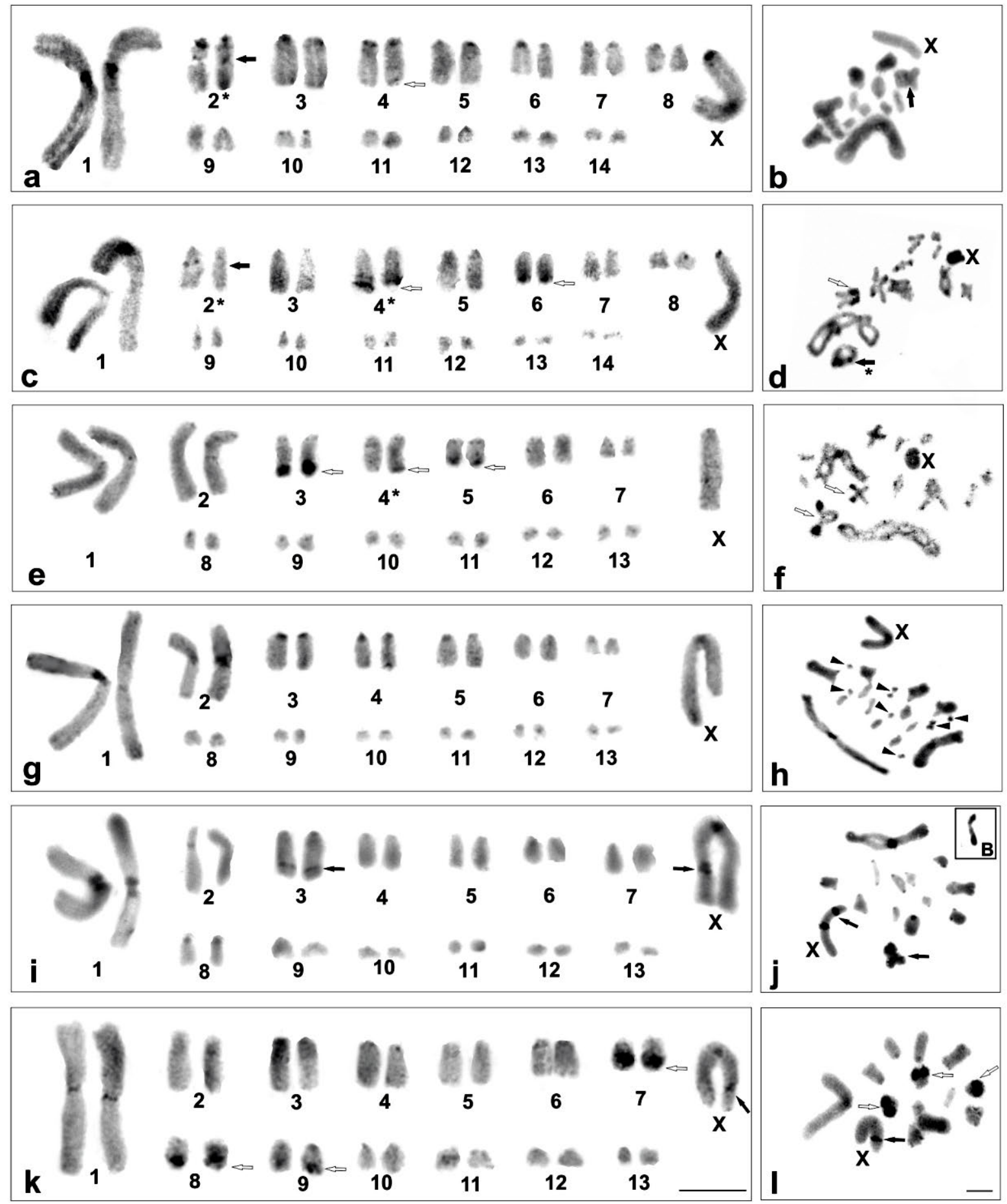

Fig. 1. C-banding of mitotic (a, c, e, g, i, k) and diakinesis/metaphase I (b, d, f, h, j, l) male chromosome complements of three Ephippigerini species: E. ephippiger (a, b), S. stalii (c, d) and S. pseudolus (e-f), and of three Bradyporini species: B. (B.) dasypus $(\mathrm{g}, \mathrm{h}), B$. (C.) m. macrogaster $(\mathrm{i}, \mathrm{j})$ and $B$. (C.) oniscus $(\mathrm{k}, 1)$. Solid arrows indicate interstitial $\mathrm{C}$-bands on $\mathrm{M}_{2}$, and those marked with an asterisk $(*)$ - heterochromatin heteromorphism (a, c, d), interstitial C-bands near the telomeric region on $\mathrm{M}_{3}$ and a thick C-band on one arm of the metacentric X chromosome (i-j). Open arrows indicate telomeric C-bands $(\mathrm{a}, \mathrm{c}-\mathrm{f}, \mathrm{k}, \mathrm{l})$ and those marked with an asterisk $(*)$ - heterochromatin heteromorphism (c, e). B chromosomes: (h) arrowheads indicate small acrocentric Bs in $B$. (B.) dasypus. $\mathrm{Bar}=10 \mu \mathrm{m}$.

content were detected on all Bradyporini chromosomes. In $B$. (B.) dasypus, the heterochromatin regions revealed by C-banding were very weakly DAPI + and $\mathrm{CMA}_{3}+$, except on the metacentric $\mathrm{L}_{1}$ with a clearly visible DAPI+/thick C-band in its paracentromeric region (Fig.
$2 \mathrm{~g}, \mathrm{~h})$. In both subspecies of $B$. (C.) macrogaster and $B$. (C.) oniscus the paracentromeric regions of most autosomes reacted positively to C-banding (Fig. 1i-l) with weak DAPI $+/ \mathrm{CMA}_{3}+$ bands (Fig. 2i-1), whereas three pairs of chromosomes with thick telomeric C-bands in $B$. 

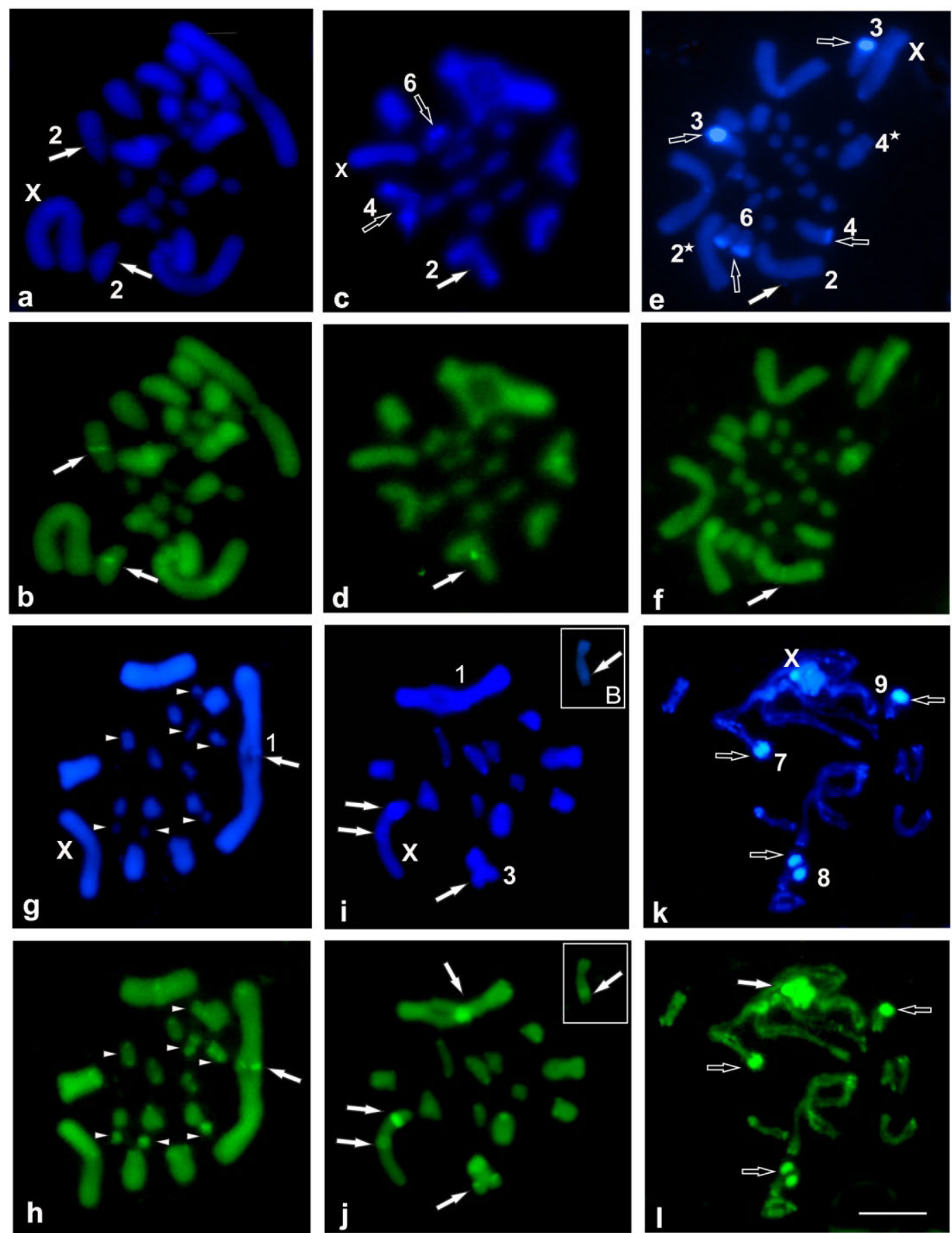

Fig. 2. DAPI (blue) and $\mathrm{CMA}_{3}$ (green) stained heterochromatin of E. ephippiger (a, b), S. stalii (c, d), S. pseudolus (e-f), B. (B.) dasypus $(\mathrm{g}, \mathrm{h}), B .\left(C\right.$.) m. macrogaster $(\mathrm{i}, \mathrm{j})$ and $B$. (C.) oniscus $(\mathrm{k}, \mathrm{l})$. Solid arrows indicate DAPI-/CMA ${ }_{3}+$ bands on $\mathrm{M}_{2}$ in mitotic metaphase $(\mathrm{a}, \mathrm{b})$ and diakinesis $(\mathrm{c}, \mathrm{d})$; on $\mathrm{L}_{2}$ in mitotic metaphase $(\mathrm{e}, \mathrm{f})$; in diakinesis $(\mathrm{g}-\mathrm{j})$ and in diplotene $(\mathrm{k}, \mathrm{l})$; with weak DAPI+/CMA 3 + bands on most autosomes, except those with clear differences in the intensity of the bands: in the paracentromeric region on the metacentric $\mathrm{L}_{1}(\mathrm{~g}, \mathrm{~h})$, on $\mathrm{L}_{1}$ and in the interstitial region on $\mathrm{M}_{3}(\mathrm{i}, \mathrm{j})$, and on the $\mathrm{X}$ chromosome (i-1). Open arrows indicate DAPI+ bands in the telomeric regions on $\mathrm{M}_{4}$ and $\mathrm{M}_{6}(\mathrm{c})$ and $\mathrm{M}_{3}, \mathrm{M}_{4}, \mathrm{M}_{6}(\mathrm{e})$ as well as DAPI+/CMA $\mathrm{C}_{3}+$ bands on $\mathrm{S}_{7-9}(\mathrm{k}, 1)$. Heteromorphism in the telomeric region on $\mathrm{M}_{4}$ and paracentromeric region on $\mathrm{L} 2$ (e) are marked with an asterisk $(*)$. B chromosomes: $(\mathrm{g}, \mathrm{h})$ arrowheads indicate small acrocentric Bs in $B$. (B.) dasypus with DAPI- bands $(\mathrm{g})$ and $\mathrm{CMA}_{3}+$ bands $(\mathrm{h})$. The inset in the top right corner shows a medium-sized $\mathrm{B}$ chromosome in $B$. (C.) m. macrogaster with very weak DAPI+ bands (i) and larger $\mathrm{CMA}_{3}+$ bands on the long arm (j) (arrows). Bar $=10 \mu \mathrm{m}$.

oniscus were intensively stained by both DAPI and $\mathrm{CMA}_{3}$ (Fig. 2k-1). B. (C.) macrogaster revealed a small subtelomeric DAPI+ block and a large $\mathrm{CMA}_{3}+$ block (with a thin C-band) on the $\mathrm{M}_{3}$ pair (Fig. 2i, j). There was a weak paracentromeric DAPI-/CMA + band (a thin C-band) and bright interstitial DAPI $+/ \mathrm{CMA}_{3}+$ band (thick C-bands) on one of the arms of the $\mathrm{X}$ chromosome in the subgenus Callimenus (Fig. 2i-1). 

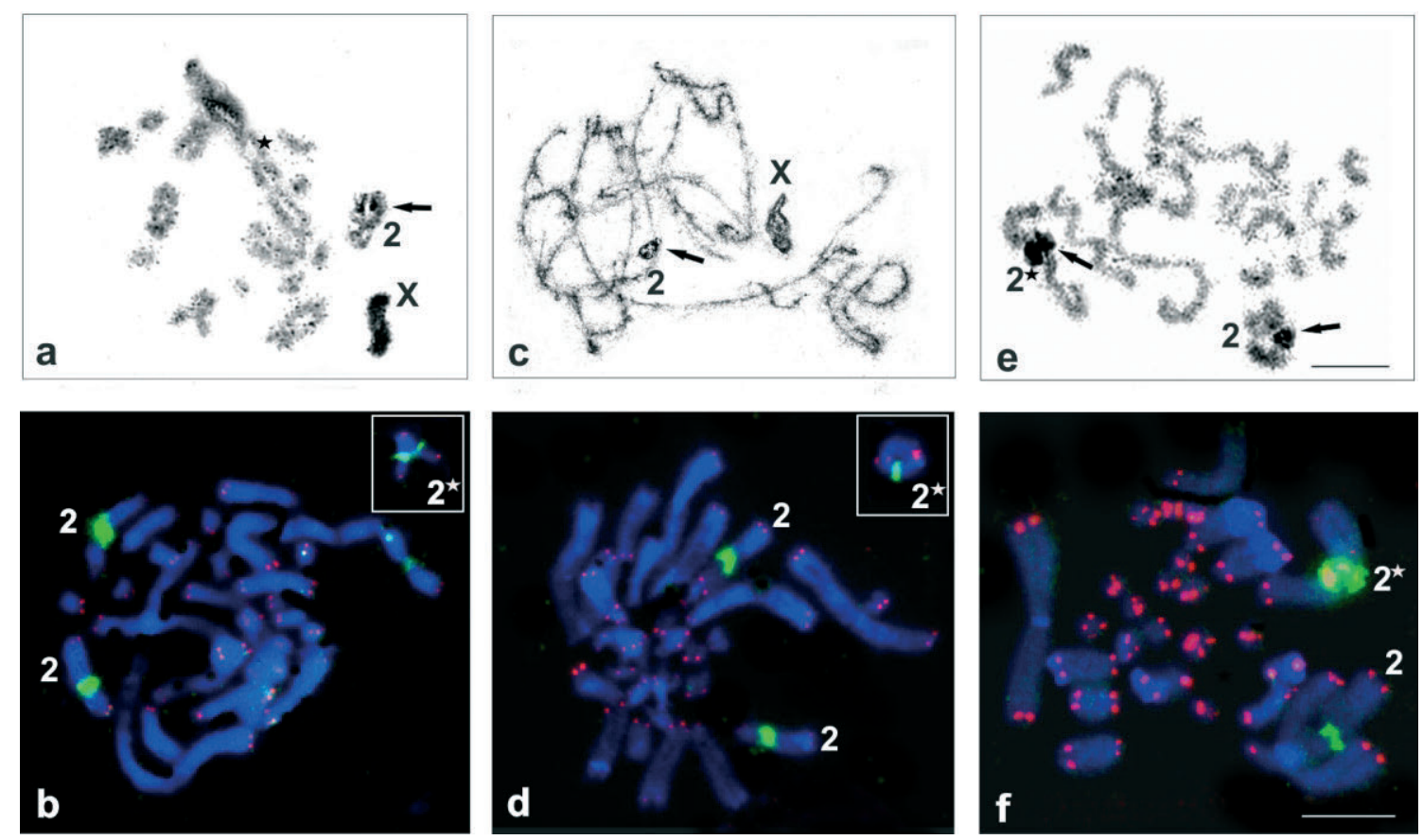

Fig. 3. Silver staining (a, c, e) and FISH using both $18 \mathrm{~S}$ rDNA probes (green) and telomeric DNA probes (red) (b, d, f) of chromosomes in Ephippigerini: E. ephippiger (a, b), S. stalii (c, d) and S. pseudolus (e, f). The arrows indicate the presence of one active NOR located in the interstitial region on $\mathrm{M}_{2}$ in diakinesis (a), early diplotene (c), and spermatogonial prophase/metaphase (d), in the paracentromeric region on $\mathrm{L}_{2}$. A cluster of $18 \mathrm{~S}$ rDNA in mitotic metaphase coincides with NORs (b, $d$, f). Hybridization areas vary in size between two homologous chromosomes: on $\mathrm{L}_{2}(\mathrm{f})$ and $\mathrm{M}_{2}$ - inset in the top right corner is individual bivalent of $E$. ephippiger (b) and S. stalii (d) - marked with an asterisk. Bar $=10 \mu \mathrm{m}$.

\section{Ag-NOR staining and FISH}

Silver staining revealed the presence of one active NOR in the interstitial region of the $\mathrm{M}_{2}$ bivalent both in $E$. ephippiger and S. stalii (Fig. 3a, c) and in the paracentromeric region on both the metacentric $\mathrm{L}_{2}$ in $S$. pseudolus and $\mathrm{L}_{1}$ in $B$. (B.) dasypus (Figs 3e, 4a). In these species, a large cluster of $18 \mathrm{~S}$ rDNA was observed at mitotic metaphase or in bivalents from diakinesis to metaphase I, coincident with a single active NOR visualized by Ag-NOR staining (Figs 3b, d, f, 4b). On the other hand, $\mathrm{AgNO}_{3}$ staining revealed the presence of two active NORs on the metacentric $\mathrm{X}$ chromosome in both $B$. $(C$.) macrogaster subspecies and in B.(C.) oniscus, a large one located interstitially on one arm and another one (observed as dots, not always seen) in the paracentromeric region (Fig. 4c-e). Additionally, small silver dots in early meiotic prophase and, sporadically, active heteromorphic NORs in mitotic metaphase were detected on $\mathrm{M}_{3}$ (Fig. 4c-e). In these taxa, three FISH signals were observed, a large cluster of $18 \mathrm{~S}$ rDNA located interstitially on the $\mathrm{X}$ chromosome and two low-intensity clusters in the paracentromeric region on both $\mathrm{X}$ and $\mathrm{L}_{1}$. Only occasionally during diakinesis in both $B$. (C.) macrogaster subspecies a fourth, low-intensity cluster of $18 \mathrm{~S}$ rDNA was detected in the interstitial region on $\mathrm{M}_{3}$ (Fig. 4f).

Following FISH with the (TTAGG) ${ }_{n}$ probe (tDNAFISH) used for spermatogonial mitoses and/or spermatocyte nuclei in meiosis (diplotene, diakinesis), signals were detected at the distal ends of each chromosome in all the taxa analyzed. Generally, the tDNA-FISH signals on the chromosomes of $S$. pseudolus were stronger than those observed in other species (Fig. 3f). No tDNA-FISH signals were observed in the centromeric region of metacentric or submeta-subacrocentric chromosomes.

\section{Heteromorphism}

Interspecific/intraspecific heterochromatin heteromorphism in respect to the heterochromatin pattern of both $\mathrm{C}$ - and fluorochrome bands as well as heteromorphism of rDNA-FISH signals were observed on some chromosomes (as indicated with an asterisk in Table 2 and in relevant figures). These chromosomes showed heteromorphism in terms of the size/strength and presence/absence of bands on respective homologous pairs. That pattern occurred in the interstitial region on $\mathrm{M}_{2}$ in both E. ephippiger (a male from Bulgaria) (Fig. 3b) and $S$. stalii (one out of three males) (Figs 1a, c, 3d), and both in the telomeric region on $\mathrm{M}_{4}$ and paracentromeric region on $\mathrm{L}_{2}$ in $S$. pseudolus (one out of two males) (Figs $2 \mathrm{e}, 3 \mathrm{f})$. Also, heteromorphism was found in the paracentromeric region on $\mathrm{L}_{1}$ in $B$. (B.) dasypus (one out of 3 individuals from population $C$ ) (Fig. $4 b$ ) as well as in the paracentromeric region on $\mathrm{L}_{1}$ and the interstitial region on $\mathrm{M}_{3}$ in $B$. (C.) $m$. macrogaster (two out of three individuals from population $A$ and laboratory culture B) (Fig. 4f).

\section{Supernumerary chromosomes and elements}

B chromosomes (Bs) were found in both B. (B.) dasypus males in one out of five populations of this spe- 

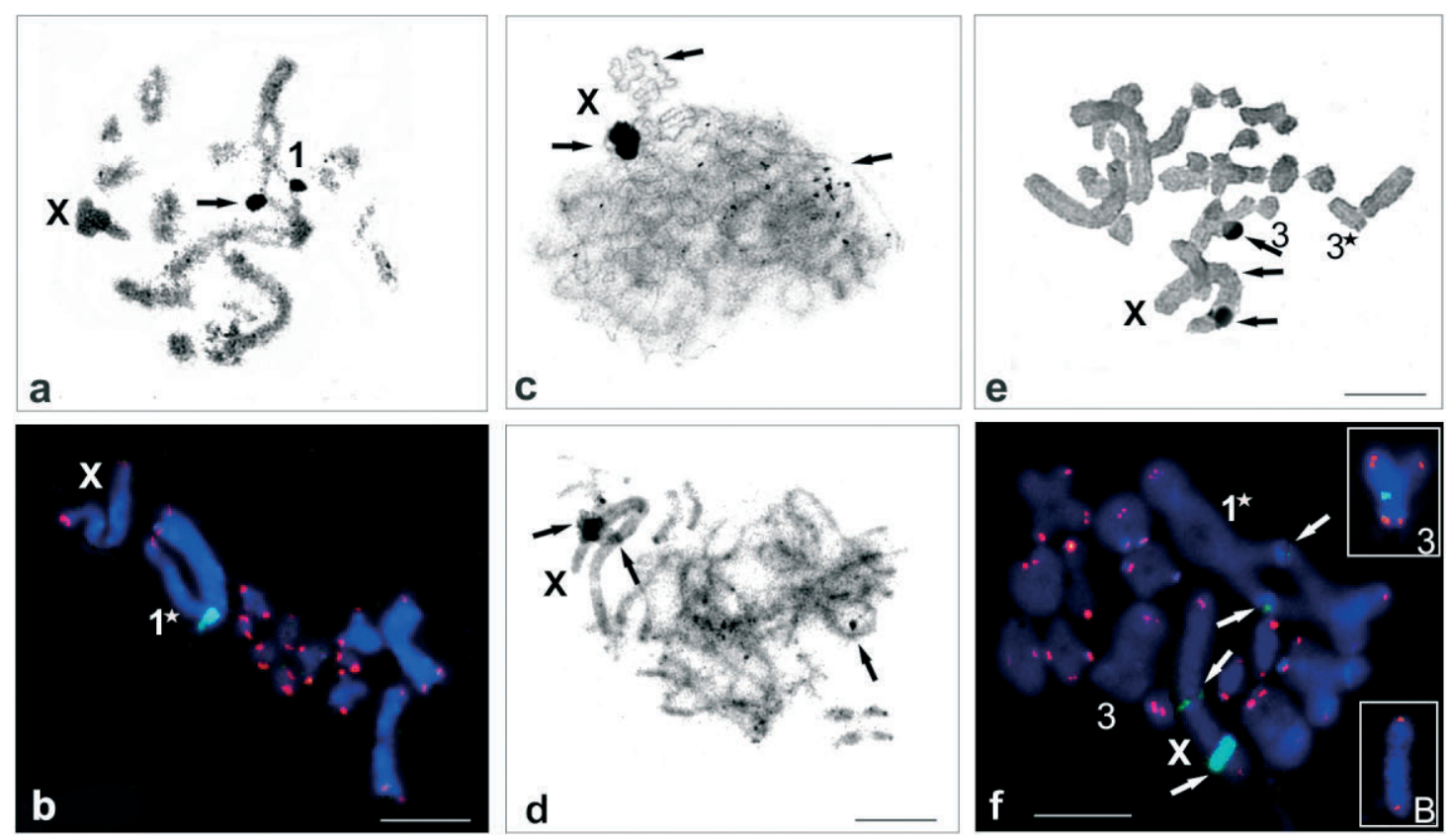

Fig. 4. Silver staining (a, c, d, e) and FISH with 18S rDNA probes (green) and telomeric DNA probes (red) (b, f) of chromosomes of Bradyporini species. B. (B.) dasypus $(\mathrm{a}, \mathrm{b})$ : arrows indicate diakinesis with one active NOR (a) and an rDNA site located in the paracentromeric region on $\mathrm{L}_{1}$ (b). B. (C.) m. macrogaster (c-f): zygotene (c), pachytene (d), spermatogonial mitosis (e), (f) diakinesis; arrows indicate two active NORs on the $\mathrm{X}$ chromosome and $\mathrm{M}_{3}$; rDNA clusters coincident with NORs (arrows) in diakinesis (f). Hybridization areas vary in size on $\mathrm{L}_{1}$ - marked with an asterisk and on $\mathrm{M}_{3}$ - inset in the top right corner (f and e). The B chromosome with a telomeric signal is inset in the bottom right corner (f). Bar $=10 \mu \mathrm{m}$.

cies (population B). They were smaller than all the autosomes, acrocentric, heterochromatic and with DAPI-/ $\mathrm{CMA}_{3}+$ band (Figs 1h, 2g, h). In twenty spermatogonial metaphases (analyzed in both individuals), the number of Bs varied from 8 to 11 , whereas in 50 diakinesis/metaphase I cells they formed 3-6 univalents and/or 5-7 bivalents. Thus, B chromosomes were mitotically and meiotically unstable and did not show a tendency to pair

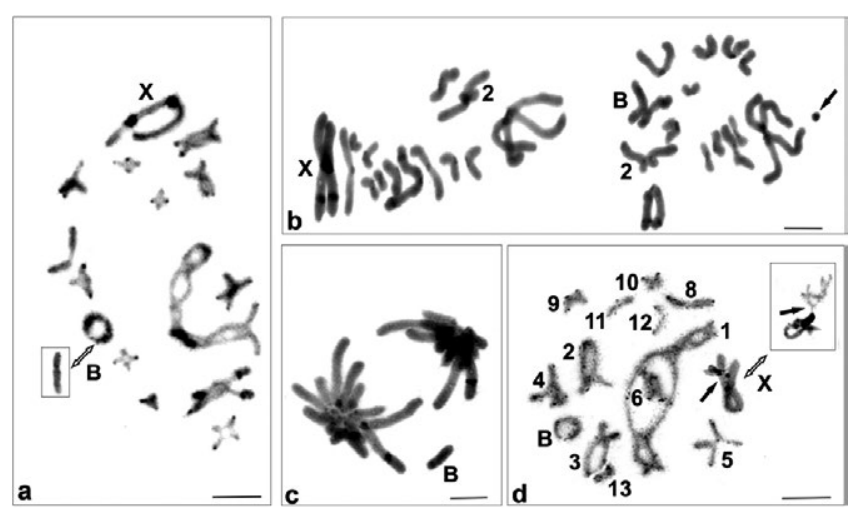

Fig. 5. The C-banding of B chromosome in B. (C.) m. macrogaster; as a bivalent or univalent (rectangle) at diplotene (a); metaphase II with and without $\mathrm{B}$, which is similar in size on $\mathrm{M}_{2}$ (b), anaphase with B (c). The first step to neo-XY sex determination; diakinesis without the $\mathrm{M}_{7}$ bivalent (d), arrows indicate the $\mathrm{X}$ chromosome connection with part of the $\mathrm{M}_{7}$ autosome during diplotene and pachytene (inset in the top right corner); a small element (arrow) (b). Bar $=10 \mu \mathrm{m}$. with $\mathrm{X}$ chromosomes or autosomes during meiosis. The individuals with Bs were not examined using FISH.

In both $B$. (C.) m. macrogaster specimens (population A), the B chromosome was similar in size to the $\mathrm{M}_{2}$ autosome, which was submetacentric with thin paracentromeric bands and weak interstitial C-bands on long arm (Fig. 1j). There were very weak interstitial DAPI+ bands and larger $\mathrm{CMA}_{3}+$ bands on the long arm of this chromosome, suggesting that the latter region contains GC-rich DNA (Fig. 2i, j). However, FISH with a ribosomal probe (18S) did not show a cluster in this region. Telomeric signals were detected at the distal ends of this chromosome (Fig. 4f). The B chromosome appeared to be negatively heteropycnotic during early meiotic prophase. From diplotene to metaphase I, this element occurred as univalent or bivalent (Fig. 5a-d). The supernumerary chromosome is probably mitotically and meiotically unstable as an XB association was never observed.

In one out of two $B$. (C.) $m$. macrogaster individuals (population A), an additional element was sporadically observed at meiotic prophase. At diplotene, a positive heteropycnotic element was clearly seen near those regions of $\mathrm{X}$ that contained an active NOR. However, during zygotene-pachytene, the $\mathrm{X}$ chromosome was probably associated with part of the $\mathrm{M}_{7}$ autosome. Thus, in some cases one of the medium-sized autosomes was not observed at diakinesis (Fig. 5d). In both individuals, some small elements were sporadically present at different meiotic stages (Fig. 5b). 
A ZICHYINI

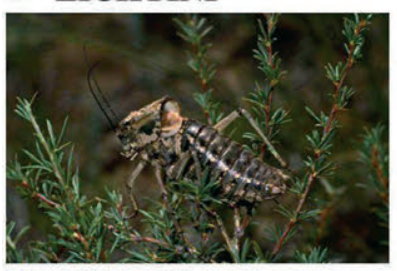

Deracantha onos

B BRADYPORINI

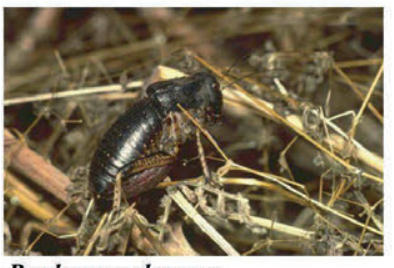

Bradyporus dasypus

\section{EPHIPPIGERINI}

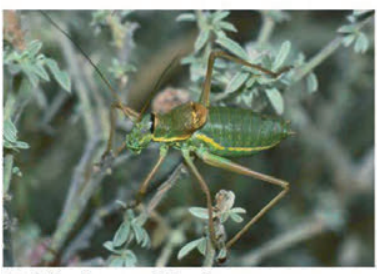

Ephippiger ephippiger

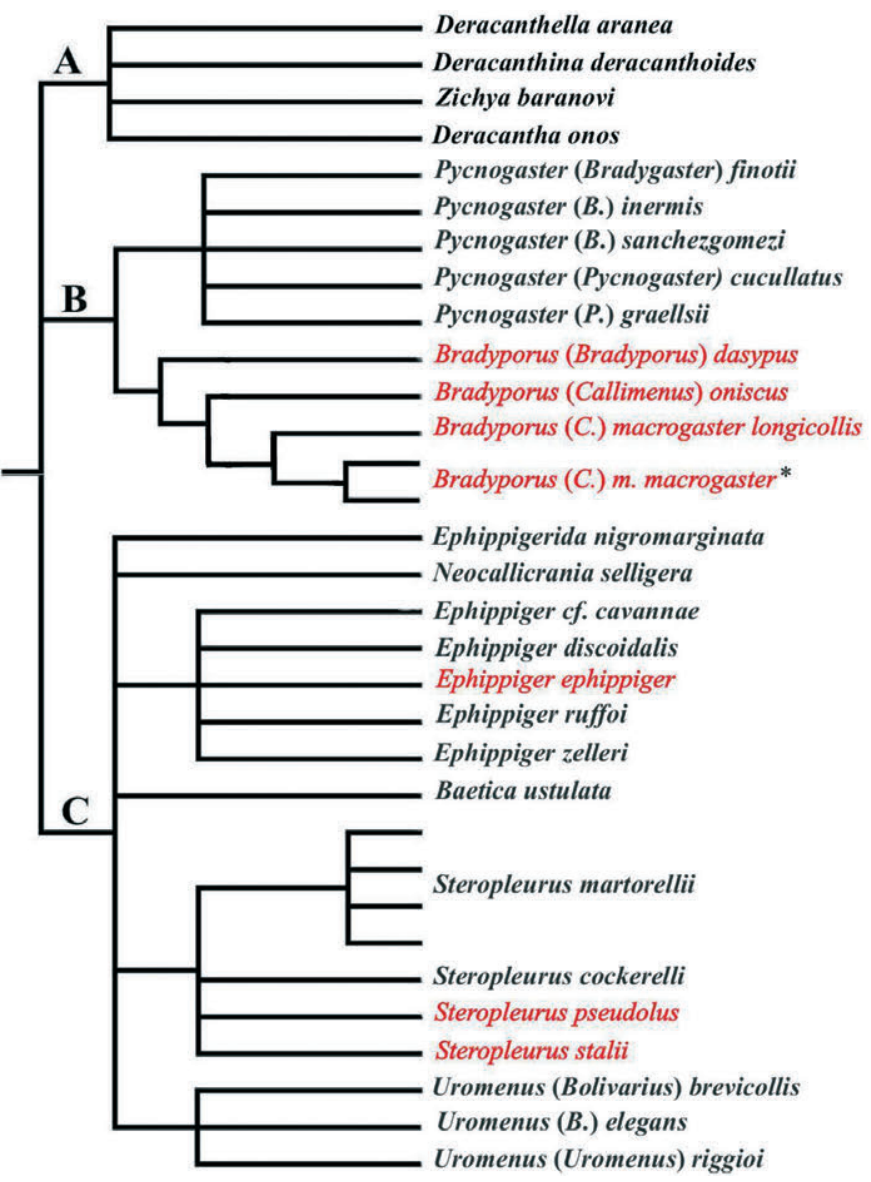

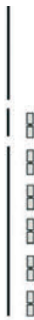

Fig. 6. Morphology and karyotype evolution. The phylogenetic scheme is based on taxonomic/morphological data (e.g., Eades et al., 2012). Information on diploid numbers of chromosomes (2n), chromosome morphology (FN) and hypothetical karyotype evolution are based on present data (marked in red) and the review by Warchałowska-Śliwa (1998). L/M $\mathrm{M}_{1-4}-$ large/medium meta-/submetacentric chromosomes resulting from Robertsonian translocations are marked with $\mathrm{Z}$; $\mathrm{Xi}$ - inversion in the $\mathrm{X}$ chromosome; tf and complex $\mathrm{tf}-$ tandem fusion and tandem fusion complex. Bradyporus $(C$.) m. macrogaster marked with an asterisk (*) have two chromosome numbers in different populations (present data and Turkoglu \& Kaca, 2002). Photos K.-G. Heller.

\section{DISCUSSION}

\section{Karyotype evolution}

Our results corroborate previous studies (for a review see Warchałowska-Śliwa, 1998), which reveal that Bradyporinae species show advanced karyotype evolution. Possible rearrangements involved in the origin of different karyotypes (the $\mathrm{X} 0$ sex determination system) are shown in Fig. 6. The diversity of diploid numbers in the subfamily probably results from the modal karyotype present in most tettigoniids, $2 \mathrm{n}=31$ in the male with acrocentric chromosomes and the $\mathrm{X} 0 / \mathrm{XX}$ sex determination mechanism reported for three genera of the tribe Zichyini (Warchałowska-Śliwa \& Bugrov, 1996). The ancestral chromosome number is reduced to $2 \mathrm{n}=29(\mathrm{FN}=31$ or 32 ) in Ephippigerini (six Ephippiger, one Ephippigerida and two Steropleurus species), Zichyini (one Deracantha species) and Bradyporini (five Pycnogaster species) as a result of one Robertsonian translocation (metacentric $\mathrm{L}_{1}$ ). This reduction may indicate a close relationship between Ephippigerini and Bradyporini if it occurred before the two tribes separated. However, since it is obvious that it occurred independently in Deracantha (Zichyini), mul- tiple reductions cannot be excluded. B. (B.) dasypus, both $B$. (C.) macrogaster subspecies and $B$. (C.) oniscus show the next step in the reduction of the chromosome number to $2 \mathrm{n}=27(\mathrm{FN}=32)$; in this case two Robertsonian translocations have affected the basic karyotype (two metacentric/ submetacentric $\mathrm{L}_{1}, \mathrm{~L}_{2}$ or $\mathrm{L}_{1}, \mathrm{M}_{2}$ pairs, respectively). The same chromosome number in S. pseudolus $(2 \mathrm{n}=27$, $\mathrm{FN}=31$ ) is clearly independently derived from a $2 \mathrm{n}=29$ karyotype, as in S. stalii (see below). Additionally, pericentric inversions modifying the position of the centromere have changed the morphology of the ancestral acrocentric $\mathrm{X}$ to the metacentric $\mathrm{X}$ chromosome in three Bradyporus species and in S. stalii. A biarmed X chromosome (subacro-/submeta-/metacentric) has also been reported in some phaneropterid species (for a review see Warchałowska-Śliwa, 1998; Warchałowska-Śliwa et al., 2008). Surprisingly, the karyotype characteristics of the B. m. macrogaster individuals collected in Turkey (Mount Spil, Manisa) by Turkoglu \& Kaca (2002), with $2 n=23(F N=32)$, X0 differ from those reported here. In this case, probably four Robertsonian fusions and a pericentric inversion in the $\mathrm{X}$ chromosome were involved in the evolution of this karyotype. The chromosomal differ- 
ences between the populations of this subspecies suggest ongoing differentiation in isolated populations. The lower chromosome numbers $(2 \mathrm{n}=25,23)$ occurring in other species have evolved by complex translocations. Four chromosomal races are described in the Steropleurus martorelli complex (Ephippigerini), a coastal species endemic to the Iberian Peninsula with diploid chromosome numbers in the male ranging from $29(\mathrm{FN}=31)$ to $23(\mathrm{FN}=27)$. Such a significant difference in the chromosome number and morphology probably results from a successive occurrence of Robertsonian and tandem fusions (Fernández-Piqueras et al., 1983a).

\section{Cytogenetic characterization}

\section{Distribution of heterochromatin}

The application of different staining techniques (classical and molecular methods) generally enables a better characterization of tettigoniid karyotypes and the identification of genus/species-specific patterns (WarchałowskaŚliwa et al., 2009, 2011). The Bradyporinae are probably characterized by autosomes with a small amount of constitutive heterochromatin in the paracentromeric region. Additionally, C-bands in the interstitial and/or telomeric regions, found in the species analyzed in this study occur in species belonging to different tribes of the subfamily (Fernández-Piqueras et al., 1983a, 1984; Navas-Castillo et al., 1986; Sentis et al., 1986; Warchałowska-Śliwa \& Bugrov, 1996, 1997).

Our results demonstrate heterogeneity in the composition of heterochromatin. The $\mathrm{CMA}_{3}$ labelled regions may coincide with $\mathrm{C}$-bands and/or with a special type of heterochromatin associated with NORs. In the Ephippigerini species $S$. stalii and $S$. pseudolus, only the telomeric regions of $\mathrm{M}_{3-5}$ showed thick C-bands and bright DAPI+ $\left(\mathrm{CMA}_{3}-\right)$ AT-rich segments. In the two aforementioned species and in E. ephippiger, CG-rich regions were only located interstitially on $\mathrm{M}_{2}$ or in the paracentromeric region on $\mathrm{L}_{2}$. $\mathrm{CMA}_{3}+$ bands and NORs are quite often associated with each other in insects, especially grasshoppers (e.g. Loreto \& Souza, 2010) and katydids (Warchałowska-Śliwa et al., 2009). In comparison with Ephippigerini, heterochromatin in Bradyporini shows a different composition; in this case, the C-blocks were $\mathrm{CMA}_{3}+$ DAPI+, carrying both AT- and CG-rich segments. Consequently, in these species the fluorochrome $\mathrm{CMA}_{3}$ did not detect actual NORs on most chromosomes, but a special type of GC-rich heterochromatin associated with this region, similar to that described in some coleopterans (e.g. Schneider et al., 2007).

Number and location of rDNA clusters (NORs)

In the Bradyporinae karyotypes described in this paper and previous studies there is usually a single NOR on a large/medium-sized autosome. Active NORs have been confirmed in E. ephippiger and S. stalii $(2 \mathrm{n}=29)$ in the interstitial region on the $\mathrm{M}_{2}$ bivalent and in the paracentromeric region on the metacentric $\mathrm{L}_{2}$ and $\mathrm{L}_{1}$ in $S$. pseudolus $(2 \mathrm{n}=27)$ and $B .(B$.$) dasypus, respectively. In these$ species, the $18 \mathrm{~S}$ rDNA loci revealed by FISH coincide with the active NORs detected by Ag-NOR staining and a bright $\mathrm{CMA}_{3}+$ band. The distribution of NORs/rDNA loci in both Steropleurus species and analysis of the relative lengths of autosomes show that a Robertsonian translocation between the second pair (with active NORs/rDNA loci) and third pair of autosomes has reduced the chromosome number from $2 \mathrm{n}=29$ ( $\mathrm{FN}=31$, with one metacentric pair), found in $S$. stalii, to $2 \mathrm{n}=27(\mathrm{FN}=31$, with two metacentric pairs) in $S$. pseudolus. Moreover, in the karyotypes of Pycnogaster cucullata, 2n $=29$ (Fernández-Piqueras, 1983c), Neocallicrania selligera (also known as Callicrania seoanei), $2 \mathrm{n}=23, \mathrm{X} 0$ (Fernández-Piqueras, 1981) and Baetica ustulata, 2n $=25$ (Navas-Castillo et al., 1986), a single active NOR was noted interstitially on the acrocentric bivalents $\mathrm{M}_{2}, \mathrm{M}_{3}$ or on the metacentric bivalent $\mathrm{L}_{2}$. These observations show that NOR-bearing autosomes take part in karyotype rearrangements. In contrast, in both species of the subgenus Callimenus there were two active NORs on the metacentric $\mathrm{X}$ chromosome, one located interstitially and the other in the paracentromeric regions, which coincided with bright and faint rDNA clusters, respectively. Cytogenetic analysis of some Odontura species in the family Tettigoniidae also revealed one or two NORs with rDNAFISH signals, located only on the sex chromosome/s of species with different sex determination systems: $\mathrm{X}(\mathrm{X} 0)$, neo-X (neo-XY) or both neo- $X_{1}$ and neo-Y (with neo$\mathrm{X}_{1} \mathrm{X}_{2} \mathrm{Y}$ ) (Warchałowska-Śliwa et al., 2011). Additionally, two or three Ag-staining areas of NORs on $\mathrm{X}, \mathrm{M}_{2}$ or on one small bivalent are recorded in Deracantha onos (Warchałowska-Śliwa \& Bugrov, 1997). Consequently, the location of active NORs in Callimenus (present paper) is another case of an unusual translocation of NORs onto sex chromosomes in tettigoniids. Probably a part of a NOR-bearing autosome was transferred to the sex chromosome/s (Warchałowska-Śliwa et al., 2011).

The (TTAGG) $)_{n}$ sequence efficiently hybridized to the ends of chromosomes in all species analyzed is typical of other Orthoptera (López-Fernández et al., 2004; Warchałowska-Śliwa et al., 2009, 2011). Differences in the intensity of the signal between species, for example, the bright tDNA-FISH signals in $U$. pseudulus compared to the weak signals in other species, may be due to a larger number of telomeric repeats. The lack of interstitial tDNA-FISH signals in the centromeric regions of meta/submetacentric chromosomes could probably be due to the loss of telomeric repeats during karyotype evolution (López-Fernández et al., 2004). Alternately, short regions of telomeric sequence may be retained but are too small to be detected using tDNA-FISH.

\section{Heteromorphism of heterochromatin and rDNA}

In some Bradyporinae species, the pattern of heterochromatin distribution has revealed size heteromorphism in the C- and fluorochrome-positive bands and NORs as well as different intensities of the rDNA hybridizationsignals on homologous pairs of autosomes (indicated by an asterisk in Table 2). Heterochromatin heteromorphism in the telomeric region of medium-sized chromosomes $\left(\mathrm{M}_{4}\right)$ may be a result of amplification of existing DNA sequences (Sumner, 1990). Our results indicate different 
intensities of hybridization signals on the autosomes of $B$. (B.) dasypus and B. (C.) $m$. macrogaster, reaching an extreme case in $S$. stalii, in an individual of which only one chromosome showed a hybridization signal, whereas its homologue did not. These differences were detected consistently by all the banding techniques and suggest the occurrence of polymorphism in the number of copies of rDNA sequences. Particular sequences may have been amplified or lost through different mechanisms, such as unequal meiotic crossing-over, homologous recombination, tandem duplication of ribosomal genes, or translocation rearrangements (e.g. Bressa et al., 2008; Cabral-de-Mello et al., 2011).

\section{B chromosomes in Bradyporinae}

The occurrence of B chromosomes has been previously noted in several tettigoniid species (for a review see Warchałowska-Śliwa et al., 2008). In Bradyporini, Lemonnier-Darcemont et al. (2009) found 35 chromosomes in the karyotype of one male Bradyporus dasypus, including 8 small B chromosomes, which were mitotically stable but meiotically unstable. In the present study, we found the same type of Bs in this species (with $2 \mathrm{n}=$ 27) only in two specimens from one of five Bulgarian populations, being, however, both mitotically and meiotically unstable. To reveal the pattern of B chromosomes in $B$. dasypus, especially in relation to its geographic distribution, more comprehensive studies are required in the future.

The next case of B chromosome occurrence in Bradyporinae is the presence of a medium-sized submetacentric $\mathrm{B}$ in two males from one B. macrogaster population (population A). B chromosomes occur in Pycnogaster cucullata, a polymorphic species with X0 and XY chromosomal races. Two types of medium-sized telocentric Bs are associated with a concomitant occurrence of several types of abnormalities affecting autosomes (Sentis \& Fernández-Piqueras, 1985). For B chromosomes, it is important to explain from which chromosome they are derived. In both cases presented in this paper, the B chromosomes are not similar to the $\mathrm{X}$ chromosome in terms of size or pycnosis and lacked any B-X association. Additionally, the results of the $\mathrm{C}$ - and fluorochrome staining (C-heterochromatin with $\mathrm{CMA}_{3}$ ) suggest that the organization of heterochromatin in $\mathrm{Bs}$ is more similar to that in autosomes. In B. macrogaster, B chromosomes have (TTAGG) $)_{n}$ repeats at the distal ends as do the autosomes. Recent cytological and molecular studies indicate that some B elements may result from interspecific hybridization between closely related species, but most likely they originate intraspecifically from their host chromosomes (Camacho et al., 2000; Teruel et al., 2010). However, in the case of the Bradyporini, it is currently not possible to explain the origin of the two types of B chromosomes, as for this one needs to compare the DNA sequences shared by both autosomes and Bs.

In the subfamily Bradyporinae, the occurrence of two chromosomal races with $\mathrm{X} 0$ and neo-XY sex determination systems was previously noted in Pycnogaster cucullata (Fernández-Piqueras et al., 1982) and Neocallicrania selligera (also known as Callicrania seoanei) (Fernández-Piqueras et al., 1981). It is worth mentioning that $B$. (C.) m. macrogaster seems to represent a complex of chromosome races, not only showing different chromosome numbers, $2 \mathrm{n}=29, \mathrm{X} 0$ (present paper) and $2 \mathrm{n}=$ 23, X0 (Turkoglu \& Kaca, 2002), but also presenting the first step towards neo-XY sex determination. Therefore, possible rearrangements (translocation of part of an autosome into the $\mathrm{X}$ chromosome, lack of one element of the set and the existence of fragments) might be the preliminary stages of chromosomal differentiation within this species.

In conclusion, the cytogenetic study presented herein constitutes the first step towards a better understanding of chromosomal organization and evolution of relationships within the Bradyporinae. Both results from the present and previous studies show that the karyotypes of the species analyzed have undergone evolution including changes in chromosome number and morphology. Robertsonian fusions between one or more autosomes and pericentric inversions in the $\mathrm{X}$ chromosome (leading to the formation of biarmed chromosomes) are a common mode of karyotype evolution within the Zichyini and Bradyporini. On the other hand, both Robertsonian and tandem fusions, and, sporadically, pericentric inversions (in the $\mathrm{X}$ chromosome) are more common in the karyotype evolution of Ephippigerini. The quantity of heterochromatin in GC-rich regions permits one to distinguish between the karyotypes of Ephippigerini and Bradyporini, at least in the species studied. The number and location of NORs/rDNA loci elucidates karyotype evolution in two species of the genus Steropleurus. On the other hand, variation in the distribution of these markers indicates that species in the genus Bradyporus, although having the same chromosome number and morphology, are not closely related to the aforementioned group, and suggests that these taxa are undergoing different patterns of karyotype evolution. The karyotype organization of Bradyporinae was analyzed using fluorochromes, silverstained NORs (Ag-NORs) and FISH for identifying the location of $18 \mathrm{~S}$ rDNA, but only one site was revealed on the autosome pairs of all the specimens tested in this study. The present study focused on detailed analysis of only six (one with two subspecies) out of 160 Bradyporinae species using classical cytogenetic methods and mapping rRNA coding genes. To reveal phylogenetic relationships within this subfamily as well as its evolutionary history, it would be necessary to conduct interdisciplinary investigations of more species, including cytogenetic studies and DNA-inferred phylogenies.

ACKNOWLEDGEMENTS. This work was partially supported by grants to T. Karamysheva from the Mianowski Fund and a project the Bulgarian Academy of Sciences and Polish Academy of Sciences. The collection of material was partly supported by grant DO 02-259/08 from the Ministry of Education, Youth and Science of Bulgaria. 


\section{REFERENCES}

BARAT J. 2007: Revisión taxonómica de los Ephippigerinae (Orthoptera: Tettigonioidea: Bradyporidae) de da Península Ibérica e Islas Baleares. I. Géneros: Callicrania Bolívar, 1898; Neocallicrania Pfau, 1996; Platystolus Bolívar, 1878 y Synephippius Navàs, 1905. - Bol. Soc. Entomol. Aragon. 40: 55-118.

Bressa M.J., Franco M.J., Toscani M.A. \& Papeschi A.G. 2008: Heterochromatin polymorphism in Holhymenia rubiginosa (Heteroptera: Coreidae). — Eur. J. Entomol. 105: $65-72$.

Bugrov A.G., Novikova O.S., Netesova E.S., Gorochov A.V. \& Blinov A.G. 2009: Using DNA sequences of two mitochondrial genes (COI and COII) for taxonomy and phylogeny of Bradyporinae katydids (Orthoptera, Ensifera, Tettigoniidae). - Euroasian Entomol. J. 8: 1-8 [in Russian].

Cabral-de-Mello D.C., Oliveira S.B., Moura R.C. \& Martins C. 2011: Chromosomal organization of the $18 \mathrm{~S}$ and $5 \mathrm{~S}$ rRNAs and histone H3 genes in Scarabaeinae coleopterans: insights into the evolutionary dynamics of multigene families and heterochromatin. - BMC Genetics 12: 88 .

Camacho J.P.M., Sharbel T.F. \& Beukeboom L. 2000: B-chromosome evolution. - Phil. Trans. R. Soc. Lond. (B) 355: $163-178$.

Cejchan A. 1967: A taxonomic study in Deracanthinae (Orthoptera, Bradyporidae). - Acta Entomol. Mus. Nat. Prag. 37: 607-633.

Eades D.C., Otte D., Cigliano M.M. \& Braun H. 2012: Orthoptera Species File Online. Version 2.0/4.1. http://Orthoptera.SpeciesFile.org. 2012/04/08

Fernández-Piqueras J., Rojo García E. \& Sentís Castaño C. 1981: A tandem fusion origin of a neo XY sex determining mechanism in the longhorned Callicrania seoanei (Bol.). Heredity 47: 397-401.

Fernández-Piqueras J., Rodriguez Campos A., Sentís Castaño C. \& Wandosell Jurado F. 1982: Pycnogaster cucullata (Charp): a polytypic species of Tettigonioidea with $\mathrm{X} 0$ and neo XY sex determination. - Heredity 48: 147-150.

Fernández-Piqueras J., Rodriguez Campos A. \& Sentís CasTAÑo C. 1983a: Hypotheses about speciation by chromosomal rearrangements in the Steropleurus martorelli complex (Tettigonioidea, Orthoptera). - Genetica 60: 167-172.

Fernández-Piqueras J., Rodriguez Campos A., Sentís Castaño C. \& Rojo-García E. 1983b: Sex chromosome evolution in the polytypic species Pycnogaster cucullata. - Heredity 50: 217-223.

Fernández-Piqueras J., Rodriguez Campos A., Sentís Castaño C. \& Rojo-García E. 1983c: Chromosomal location of the active NOR in the Steropleurus martorelli complex. Genetica 61: 9-12.

Fernández-Piqueras J., Rodriguez A., Sentís Castaño C. \& Rojo-García E. 1984: Cheterochromatin variation in the monospecific genus Baetica (Orthoptera: Tettigoniidae). Caryologia 37: 69-76.

Lemonnier-Darcemont M., Dutrillaux A.-M., Dutrillaux B. \& Darcemont C. 2009: Summary of knowledge on Bradyporis dasypus (Illiger, 1880) (Orthoptera: Tettigoniidae). Articulata 24: 15-29.

Levan A., Fredga K. \& Sandberg A.A. 1964: Nomenclature for centromeric position of chromosomes. - Hereditas 52: 201-220.

López-Fernández C., Pradillo E., Zabal-Aguirre M., Fernández J.L., García de la Vega C. \& Gisávelez J. 2004 Telomeric and interstitial telomeric-like DNA sequence in Orthoptera genomes. - Genome 47: 757-763.
LoReto V. \& Souza M.J. 2010: Karyotype, constitutive heterochromatin and nucleolar organizer regions (NORs) in Belosacris coccineipes (Acrididae - Leptysminae). - Gen. Mol. Biol. 23: 575-579.

NADIG A. 1994: Revision of the genus Uromenus Bolivar, 1878 (Orthoptera: Ephippigeridae). — Rev. Suisse Zool. 101: 919-1016.

Navas-Castillo J., Cabrero J. \& Camacho J.P.M. 1986: Heterochromatin variation in Beatica ustulata (Orthoptera: Tettigoniidae) analysed by $\mathrm{C}$ and G-banding. - Heredity 56: 161-165.

Peinado M.V. 1990: Tettigonioideos espanoles (Ephippigerinae). $\mathrm{PhD}$ Thesis, Universidad Complutense de Madrid, 411 pp.

PFAU H.K. 1988: Untersuchungen zur Stridulation und Phylogenie der Gattung Pycnogaster Graells, 1851 (Orthoptera, Tettigoniidae, Pycnogasterinae). - Mitt. Schweizer. Entomol. Ges. 61: 167-183.

PfaU H.K. 1996: Bioacoustics and evolution of Platystolus Bolivar (Ensifera, Tettigoniidae). — Tijdschr. Entomol. 139: 33-72.

Pfau H.K. \& Pfau B. 1995: Bioacoustics and evolution of the Pycnogastrinae (Orthoptera, Tettigoniidae): Pycnogaster valentini Pinedo and Llorente, 1986 and Pycnogaster cucullata (Charpentier, 1825). - Mitt. Schweizer. Entomol. Ges. 68: 465-478.

Schneider M.C., Rosa S.P., Almeida M.C., Costa C. \& Cella D.M. 2007: Chromosomal similarities and differences among four Neotropical Elateridae (Conoderini and Pyrophorini) and other related species, with comments on the NOR pattern in Coleoptera. - J. Zool. Syst. Evol. Res. 45: 308-316.

SCHWEIZER D. 1976: Reverse fluorescent chromosome banding with chromomycin and DAPI. - Chromosoma 58: 307-324.

Sentis C. \& Fernández-Piqueras J. 1985: The B chromosomes of Pycnogaster cucullata (Charp.) and their effects on the A complement. - Heredity 55: 375-380.

Sentis C., Santos J. \& Fernández-Piqueras J. 1986: C-heterochromatin polymorphism in Baetica ustulata: intraindividual variation and fluorescence banding pattern. - Chromosoma 94: $65-70$

SumNer S.G. 1972: A simple technique for demonstrating centromere heterochromatin. - Exp. Cell. Res. 75: 304-306.

SuMner A.T. 1990: Chromosome Banding. Unwin Hyman, London, $434 \mathrm{pp}$

Teruel M., Cabrero J. Perfectti F. \& Camacho J.P.M. 2010: B chromosome ancestry revealed by histone genes in the migratory locust. - Chromosoma 119: 217-225.

Turkoglu S. \& Kaca S. 2002: Karyotype, C- and G-band patterns and DNA content of Callimenus (= Bradyprus) macrogaster macrogaster. - J. Insect. Sci. 2:24, Available online: insectscience.org/2.24

ÜNAL M. 2011: Taxonomic review of the subfamily Bradyporinae (Orthoptera: Tettigoniidae; Bradyporini; Ephippigerini) of Turkey, with description of new species and the relationship of the taxa. - Zootaxa 2899: 1-42.

WARCHA£OWSKA-ŚLIWA E. 1998: Karyotype characteristics of katydid orthopterans (Ensifera, Tettigoniidae) and remarks on their evolution at different taxonomic levels. - Folia Biol. (Kraków) 46: 143-176.

WarchaŁOWSKA-ŚLIWA E. \& Bugrov A.G. 1996: Karyotypes and C-banding patterns of Bradyporinae (Orthoptera, Tettigoniidae). - Folia Biol. (Kraków) 44: 95-98.

WarchatowsKa-Śliwa E. \& Bugrov A.G. 1997: C-heterochromatin variation in Deracantha onos (Pall.) (Deracanthini, Bradyporinae, Tettigoniidae, Orthoptera). - Cytologia 62: $7-12$. 
WarchąOWSKa-ŚlIWA E. \& MaryańSKa-NadaChOWSKA A. 1992: Karyotypes, C-bands, NORs location in spermatogenesis of Isophya brevipennis Brunner (Orthoptera: Phaneropteridae). - Caryologia 45: 83-89.

Warchalowska-Śliwa E., Chobanov D., Grzywacz B. \& MARYAŃSKA-NADACHOWSKA A. 2008: Taxonomy of the genus Isophya (Orthoptera, Phaneropteridae, Barbitistinae): Comparison of karyological and morphological data. - Folia Biol. (Kraków) 56: 227-241.

WarchąOWSKa-Śliwa E., Grzywacz B., MaryańsKaNadachowska A., Karamysheva T.V., RubTsov N.B. \& Chobanov D.P. 2009: Chromosomal differentiation among bisexual European species of Saga (Orthoptera, Tettigoniidae,
Saginae) detected by both classical and molecular methods. - Eur. J. Entomol. 106: 1-9.

Warchalowska-Śliwa E., Maryańska-Nadachowska A., Grzywacz B., Karamysheva T., Lehmann A.W., Lehmann G.U.C. \& Heller K.-G. 2011: Changes in the numbers of chromosomes and sex determination system in bushcrickets of the genus Odontura (Orthoptera, Tettigoniidae, Phaneropterinae). - Eur. J. Entomol. 108: 183-195.

Zhou Z., Huang Y., Shi F. \& Ye H. 2009: The complete mitochondrial genome of Deracantha onos (Orthoptera: Bradyporinae). - Mol. Biol. Rep. 36: 7-12.

Received June 13, 2012; revised and accepted August 8, 2012 